\title{
Missense mutations in DYT-TOR1A dystonia
}

Neurol Genet 2019;5:e350. doi:10.1212/NXG.0000000000000350

In the article "Missense mutations in DYT-TOR1A dystonia" by Iqbal et al., ${ }^{1}$ first published online June 6, 2019, the genotype under patient IV-1 in panel A of the figure should have read "M/-." Additionally, the third label in the second row of panel A in the same figure should read "II-3." The editorial office regrets the errors.

Figure

A

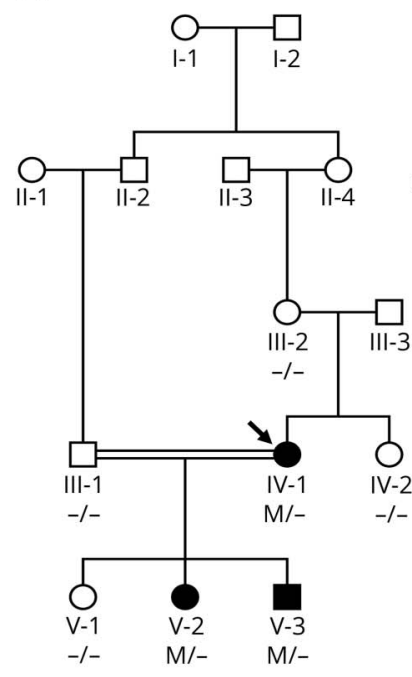

$E$

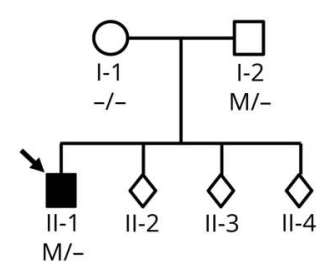

B

chr9: g.132576316(hg19);c.934A>G

Normal sequence

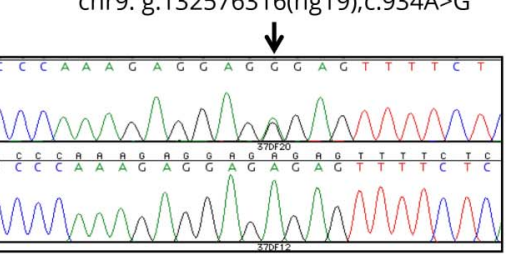

C

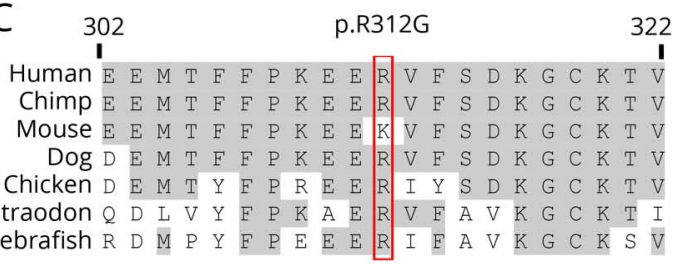

D

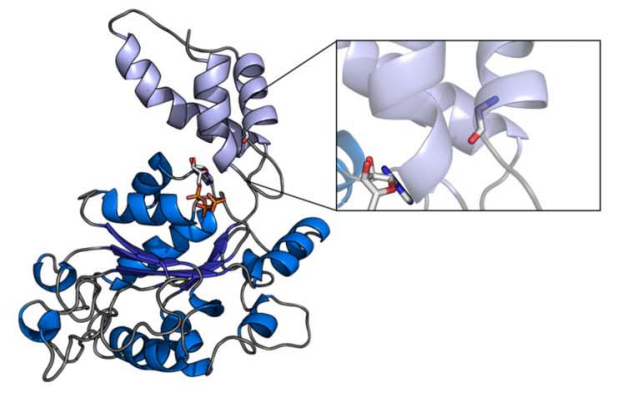

$\mathrm{F}$

chr9: g.132576387(hg19);c.863G>A

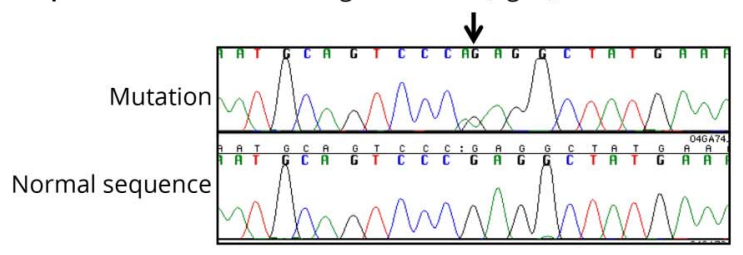

\section{REFERENCE}

1. Iqbal Z, Koht J, Pihlstrøm L, et al. Missense mutations in DYT-TOR1A dystonia. Neurol Genet 2019;5:e343. 


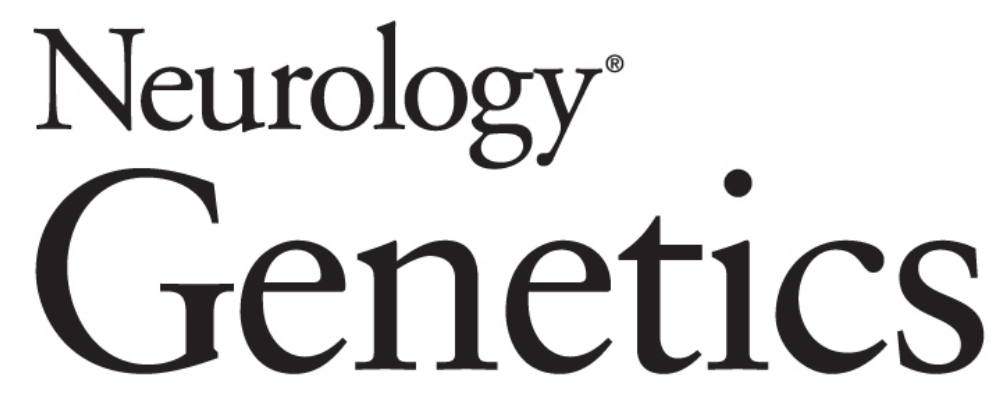

\section{Missense mutations in DYT-TOR1A dystonia \\ Neurol Genet 2019;5; \\ DOI 10.1212/NXG.0000000000000350}

This information is current as of August 15, 2019

Updated Information \& Services

References

Permissions \& Licensing

Reprints including high resolution figures, can be found at: http://ng.neurology.org/content/5/4/e350.full.html

This article cites 1 articles, 1 of which you can access for free at: http://ng.neurology.org/content/5/4/e350.full.html\#\#ref-list-1

Information about reproducing this article in parts (figures,tables) or in its entirety can be found online at:

http://ng.neurology.org/misc/about.xhtml\#permissions

Information about ordering reprints can be found online: http://ng.neurology.org/misc/addir.xhtml\#reprintsus

Neurol Genet is an official journal of the American Academy of Neurology. Published since April 2015, it is an open-access, online-only, continuous publication journal. Copyright ( 2019 American Academy of Neurology. All rights reserved. Online ISSN: 2376-7839.

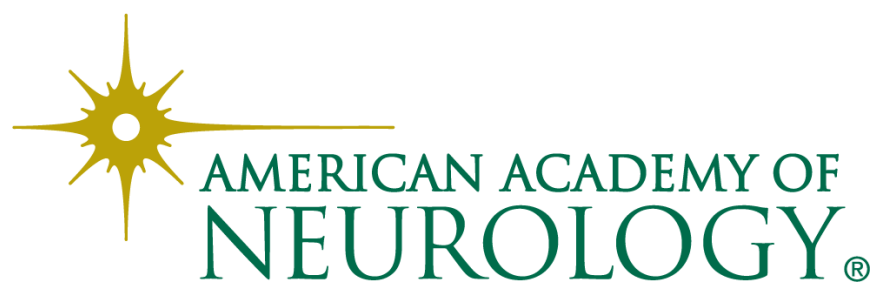

